\title{
Screening methodology for bank erosion estimation at pipeline watercourse crossings
}

\author{
G. Ferris \& S. Newton \\ $B G C$ Engineering Inc., Calgary, Canada
}

\begin{abstract}
A screening level model was developed to estimate bank erosion at pipeline watercourse crossings to provide estimates of the probability of pipeline exposure resulting from various extreme flood events. The model uses estimates of flood duration and maximum water velocity during flooding to predict the amount of bank erosion that would occur and compares the results to the horizontal "setback" distance. When the predicted horizontal erosion is equal to horizontal distance between the pipeline and the bank position, the probability of that flood occurring is equal to the probability of pipeline exposure due to bank erosion. The results of the bank erosion calculation can then be compared to: the probability of the flood causing exposure by scour and/or avulsion; regulatory acceptance criteria for pipelines; and company integrity objectives to assess the need for additional investigation or proactive mitigation.
\end{abstract}

\section{INTRODUCTION}

Pipeline failures (leaks or ruptures) caused by hydrotechnical forces at watercourse crossings occur on an infrequent basis compared to other causes of pipeline failure, such as third party damage or corrosion (Jeglic 2004, Cunha 2012). The pipeline industry typically combines watercourse crossing and slope instability failures as ground movement (AER 2013) or as part of "natural force" failures. When ground movement failures are separated into their respective categories, about half of the pipeline failures are caused by watercourses (Cunha 2012). In the Canadian province of Alberta, ground movement accounted for $1.7 \%$ of all failures between 1990 and 2012 (AER 2013), suggesting that approximately $0.85 \%$ of all pipeline failures were caused by watercourses.

Despite this low failure percentage, ground movement failures, and particularly watercourse crossing failures, tend to result in higher costs and more negative public attention than other types of failures (Porter et al. 2014). This is especially true of crude oil or other nonvolatile liquids pipelines, but less so for natural gas or volatile liquids, as visible signs of the release generally do not persist and cleanup is less onerous for those types of products.

Floods at watercourse crossings can lead to pipeline exposure and failure. The rate of pipeline failure has been reported to be about two orders of magnitude less than the rate of pipeline exposure, so that the frequency of failure per exposure is estimated to be 1 in 132 (Dooley et al. 2014). Failures can occur as a result of exposures in the bed of the channel (due to scour or degradation), as a result of lateral channel migration (bank erosion) or new channel formation (avulsion). For example, several pipeline crossings of the San Jacinto River in Texas failed as a result of severe flooding in 1994 (NTSB 1996) by these various mechanisms.

Pipeline owners and operators in Canada are required by regulations to implement integrity management programs with the goal of preventing pipeline failures. For watercourse crossings, predictive models can be used to estimate the probability of pipeline exposure. When combined with vulnerability assessments (Dooley et al. 2014), a prediction of the probability of pipeline failure is achieved. Appropriate management actions can then be taken to prioritize crossings for mitigation and reduce the probability of failure.

As part of pipeline integrity programs, operators are required to assess hundreds to thousands of watercourses that intersect their pipeline networks (Bracic et al. 2014, Porter et al. 2014), with some operators reporting more than 50,000 watercourse crossings. As a result, screening level models are needed to focus resources on sites with the highest likelihood of failure.

To fully assess the crossings, models should be able to evaluate all hydrotechnical hazards that could lead to pipeline exposure, including scour, bank erosion and avulsion. The models should also adequately assess the vulnerability of the pipeline to failure 
by considering the pipeline's potential for water loading, impact by the channel substrate and debris, as well as fatigue failure caused by vortex induced vibration (VIV) of a free spanning section of pipeline. Long free spans affected by VIV have resulted in the majority of onshore pipeline watercourse crossing failures (Ferris et al. 2015).

This paper presents the part of the watercourse crossings assessment model used to complete screening level estimates of the probability of pipeline exposure due to bank erosion. The method is used alongside other screening level algorithms for evaluating scour and avulsion. The data inputs for the model are collected based on brief site visits (e.g. $<1$ hour) and desktop studies, and include relevant information regarding the watercourses and pipelines.

\section{METHODOLOGY}

The screening method focuses on bank erosion expected to result from a single flood event to determine the magnitude of flood required to expose the pipeline. This model is used as part of an overall watercourse management program, which includes completing repeat inspections of watercourse crossings at a frequency commensurate with the probability of pipeline failure and exposure (Baumgard et al. 2014). If progressive erosion is occurring and reducing the distance between the bank and the pipeline, then the return period of the flood that would cause exposure is reduced based on updated information captured through the use of repeat site visits.

The main elements of the methodology include: estimating the discharge magnitude probability relationship (flood frequency analysis); estimating the time to peak of a typical flood; assuming or determining the unit flood duration relationship; estimating the average water velocity for each flood probability; determining the water velocity affecting each bank of the watercourse; estimating the threshold velocity to initiate erosion on each bank (based on soil type and vegetation) and finally, estimating the maximum erosion rate that would occur given the predicted maximum velocity (following Briaud 2008).

Water velocity is used as the basis of the method, although shear stress is likely a better predictor of the limit between the erosion-no erosion boundary (Briaud 2008, Briaud et al. 2011). The use of velocity allows for field calibration of the results, such as: a direct comparison of the predicted velocity to the measured velocity during a high flow event, as well as the development of a local velocity erosion rate relationship based on either a series of flood events and measured erosion rates, or a relationship based on field scale testing (Briaud et al. 2011).

Bank erosion is controlled by the relationship between erosion forces acting on the bank and the re- sistance of the bank (Rosgen 1996). Erosion forces are related to flow stage, width to depth ratio of the channel, position in planform (i.e. inside or outside bend) and the local velocity. Resistance is determined based on soil type, vegetation and other soil binding factors.

\subsection{Flood hydrographs}

Flood hydrographs (or unit hydrographs) describe changes to flow magnitude above base flow as a function of time. The Soil Conservation Service (SCS) in the USA created a dimensionless unit hydrograph (Watt et al. 1989) to describe the flow magnitude versus time relationship of a flood event. An example is shown in Figure 1. Time and discharge have been normalized by the time to reach the peak flood, $t_{p}$, and the peak discharge, $Q_{p}$, respectively.

For the screening method, the flood hydrograph shape was simplified to consist of a triangular area with a total base time that is three times the time to peak.

The time and discharge relationship can vary significantly from the assumptions made in this method (Watt et al. 1989), but following the general approach described by Alberta Transportation (Alberta Transportation 2006), this simplification appears justified for screening level methods.

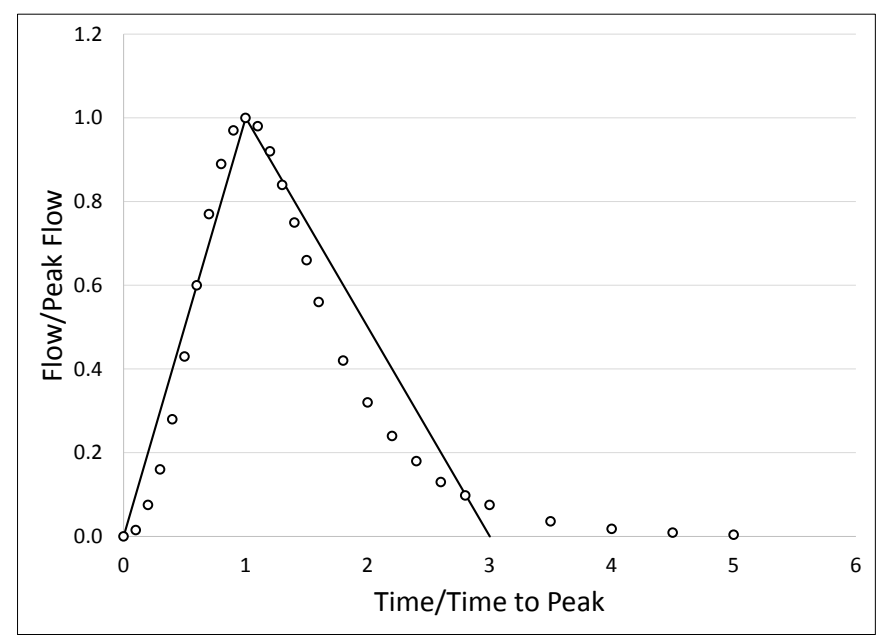

Figure 1. Flood hydrograph. Points show the SCS relationship. Lines show the assumed hydrograph shape.

\subsection{Peak discharges, $Q_{p}$}

The Water Survey of Canada (WSC), maintains a network of stream gauge stations to monitor the water elevation and discharge at approximately 1,800 hydrometric gauge stations in Canada. The WSC also provides access to historical data at over 7,600 stations. For every year that a station has been in operation, daily discharge data can be used to determine the annual maximum instantaneous peak flow. Using a flood frequency analysis (FFA) and the historical peak flow record, the annual likelihood of oc- 
currence of various peak flood magnitudes can be determined for the gauge station location (Leopold, 1994, Watt et al. 1989).

An interconnected river network was developed for all river basins in Canada and the USA (Ferris et al. 2015) and is used to produce screening level FFAs for each watercourse crossing of the pipeline network. A screenshot from the river network's geographic information system (GIS) display is shown in Figure 2. Every individual stream segments within the network contains data regarding its Strahler stream order, local catchment area, total catchment area, and local gradient.

When a pipeline-watercourse intersection is identified in the GIS-based database, an algorithm is used to identify appropriate gauges (Ferris et al. 2015) to calculate FFAs for each crossing using either regional analysis or pro-rated methods (Leopold, 1994). The accuracy of the FFA depends on: the number and quality of available gauges, length of record available, and differences in catchment area between the site and the gauges. The FFA provides a prediction of both the average flow expected at each crossing location, and a prediction of extreme floods that could be expected, typically up to the 500-year flood (a flood with a 0.002 probability of occurrence).

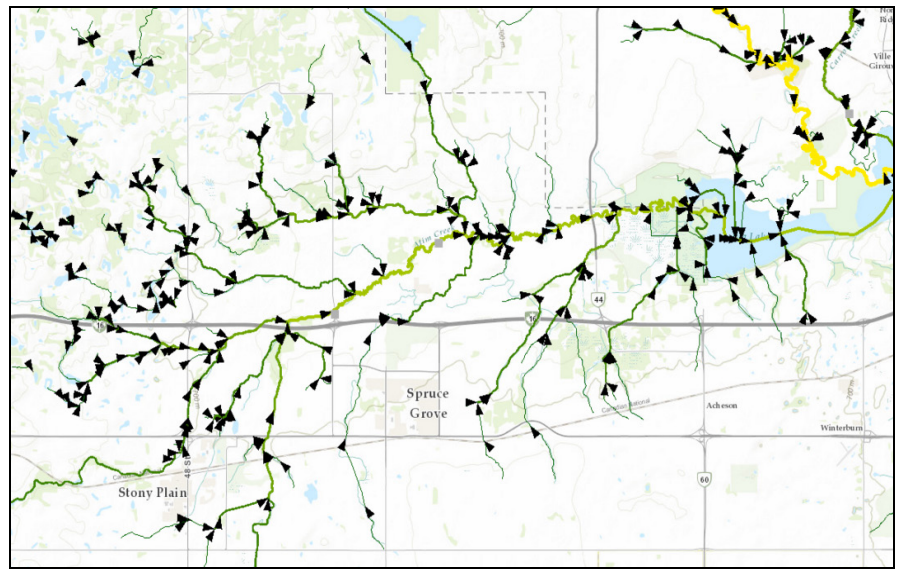

Figure 2. Screenshot from the river network, showing stream and river locations. Line widths thicken with increasing Strahler stream order and arrows show the direction of flow.

\subsection{Time to peak, $T_{p}$}

The time to the peak of a flood event can be determined by examining historical flood events measured by the same WSC gauge stations that were used to generate the FFAs. The standard method (Watt et al. 1989) of determining a peak flood that is associated with an event (rainfall, or rain-on-snow) is undertaken. Once the peak is identified, the base flow is removed to determine the total duration of the event. The time from the onset of the event until the peak is reached is the time to peak. This has been completed for more than 3,800 individual flood events in Alberta (Alberta Transportation 2006), as shown in Figure 3.

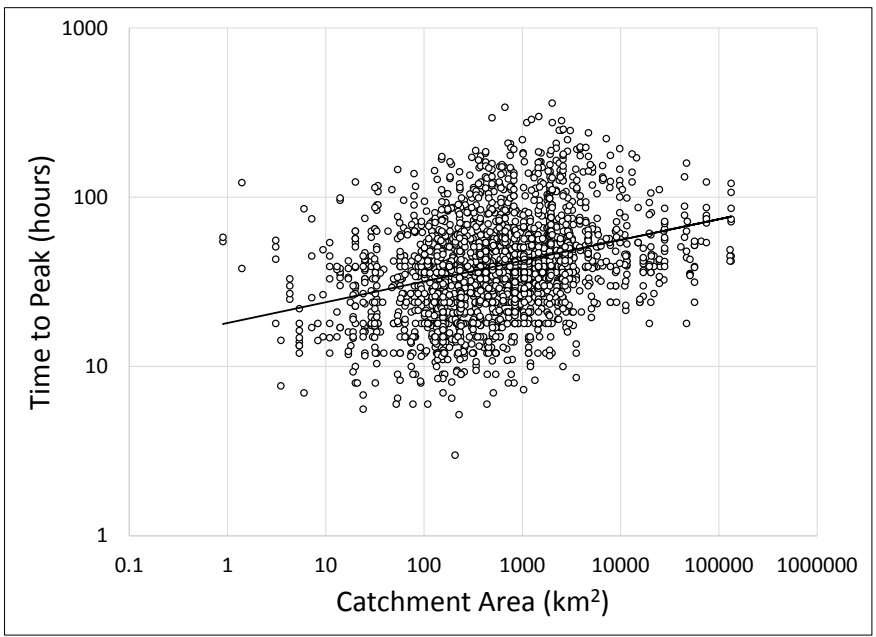

Figure 3. Catchment area versus time to peak relationship for Alberta WSC gauges.

Figure 3 shows extensive scatter due to two main controls; climate variability across the province, and a wide range of flood magnitudes, representing floods with return periods from less than 2 to more than 250 years. Climate variability can be understood by examining the variability of event basin yield. The event basin yield (expressed in $\mathrm{mm}$ ), is obtained by dividing the volume of water in a flood event by the catchment area. This was completed for the events shown in Figure 3 and resulted in an order of magnitude spread, ranging from 15 to $150 \mathrm{~mm}$ (Alberta Transportation 2006).

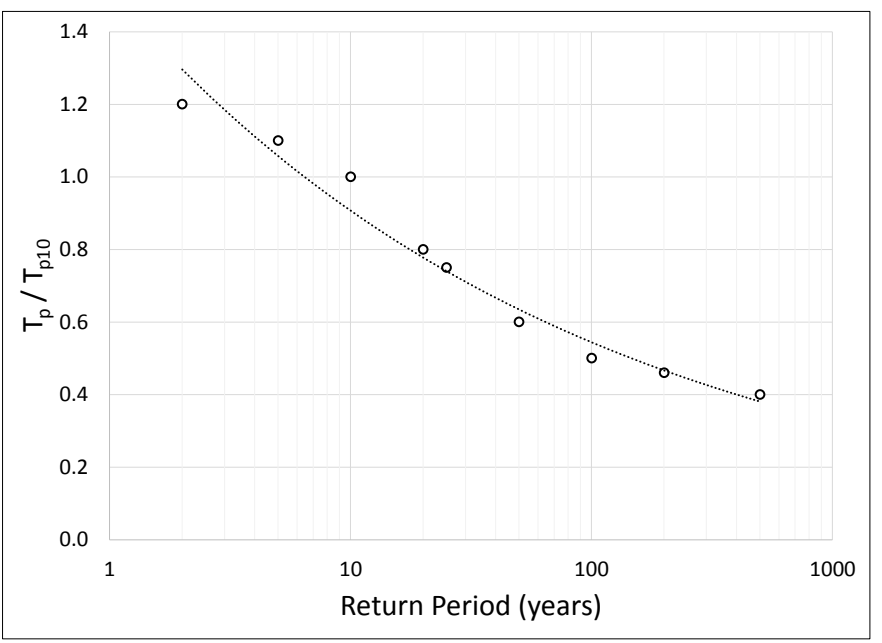

Figure 4. Return period versus time to peak relationship (normalized to 10 year return period flood).

An example relationship between time to peak and return period of an event is included in Figure 4, which shows that the time to peak for an extremely large flood (500 year return period) is about $40 \%$ shorter that the time to peak for the 10 year flood. This relationship is expected to vary by hydrogeographic region, but is reflective of the combined snowmelt and rainfall relationships of the Canadian 
Prairie provinces. Correcting for these two factors produces a relatively strong relationship between time to peak and catchment area.

\subsection{Water velocities}

The crossing-specific FFA relationship is used to predict the depth of water and water velocity expected for each return period flood. The screening level assessment uses the one dimensional Manning's equation (Equation 1) to convert discharge rate to the average depth of water and water velocity:

$$
Q=\frac{1}{n} \times A \times d^{2 / 3} \times s^{1 / 2}
$$

where: $Q=$ discharge $\left(\mathrm{m}^{3} / \mathrm{s}\right) ; A=$ cross-sectional area of the channel $\left(\mathrm{m}^{2}\right) ; d=$ average flow depth (m); $s=$ channel slope $(\mathrm{m} / \mathrm{m})$; and $n=$ Manning's flow resistance value.

The relationship between water discharge and the depth of water at the crossing varies based on the channel cross-section, gradient and roughness, which are dependent on local characteristics such as channel configuration (planform and section), soil type, and vegetation. For the purposes of the screening assessment, a constant roughness was assumed; gradients were measured using the river network; and generalized cross-sections were created based on three channel width measurements that are collected during field inspections or channel surveys. These measurements are: bankfull width (top surface width of the 2-year flood), active floodplain (top surface width of the 10-year flood), and floodplain (top surface width of the 100-year flood).

These are used to create the cross-section in the following way: 1) create a rectangle where the width is equal to the bankfull width and the depth is calculated using the 2-year discharge; 2) create a trapezoid with the base width equal to the bankfull width and the top of the trapezoid width equal to the active floodplain width and then calculate the depth of water by transferring the 10-year flood through the rectangle (from Step 1) and the upper trapezoid (the height is modified until the discharge passes through the section); 3) assume that the slope of the ground between the active floodplain and the floodplain is $0.5 \%$; and 4) assume that the slope of the ground is $2 \mathrm{H}: 1 \mathrm{~V}$ beyond the floodplain limits.

These measurements and calculations define the cross-section shape of the channel that is then used, along with Equation 1, to determine the water depth and average water velocity for the other return period floods.

The average water velocity is then adjusted to reflect the water velocity that is expected to affect each of the banks. The velocity is modified for the planform arrangement and for the local bank slope. According to the United States Army Corps of Engi- neers (USACE) (Thorne and Abt 1993), the planform arrangement of the channel can change the water velocity by as much as $50 \%$. The factors applied to velocities according to channel planform are shown in Table 1. The channel planform is measured in the field during the site inspection and then checked using aerial photography. A similar type of velocity reduction occurs based on the geometry of the channel bank. For example, if the slope of the bank is less than 40 degrees, the velocity that acts on the bank is reduced due to the lower flow depth of the water near the bank. Factors are applied to shallower bank angles to reduce the effective velocity. The bank angle is measured in the field during the site visit.

Table 1 . Variation in velocity according to channel planform.

\begin{tabular}{lcc}
\hline Planform & $\begin{array}{l}\text { Factor to modify } \\
\text { inside bend velocity }\end{array}$ & $\begin{array}{l}\text { Factor to modify } \\
\text { outside bend velocity }\end{array}$ \\
\hline Straight & 1 & 1 \\
Gentle bend & 0.9 & 1.1 \\
Moderate bend & 0.8 & 1.2 \\
Severe bend & 0.65 & 1.35 \\
$90^{\circ}$ bend & 0.5 & 1.5 \\
\hline
\end{tabular}

Once the average velocities have been modified to reflect the conditions of each bank, a table is generated for each watercourse crossing with predicted time to peak and water velocities affecting each bank at various return period floods. An example for a pipeline crossing of the James River in central Alberta is provided in Table 2. An air photograph of the crossing is shown in Figure 5; the right bank is on the outside bend of the meander.

Table 2. Example flood duration and velocity calculation for James River, Alberta.

\begin{tabular}{lccc}
\hline $\begin{array}{l}\text { Flood return } \\
\text { period }\end{array}$ & $\begin{array}{l}\text { Time to } \\
\text { peak } \\
\text { hours }\end{array}$ & $\begin{array}{l}\text { Right bank } \\
\text { velocity } \\
\mathrm{m} / \mathrm{s}\end{array}$ & $\begin{array}{l}\text { Left bank } \\
\text { velocity } \\
\mathrm{m} / \mathrm{s}\end{array}$ \\
\hline 2 & 116 & 1.60 & 0.61 \\
5 & 95 & 1.78 & 0.68 \\
10 & 82 & 1.84 & 0.70 \\
20 & 70 & 2.00 & 0.76 \\
50 & 57 & 2.38 & 0.90 \\
100 & 49 & 2.63 & 1.00 \\
200 & 42 & 2.87 & 1.09 \\
\hline
\end{tabular}




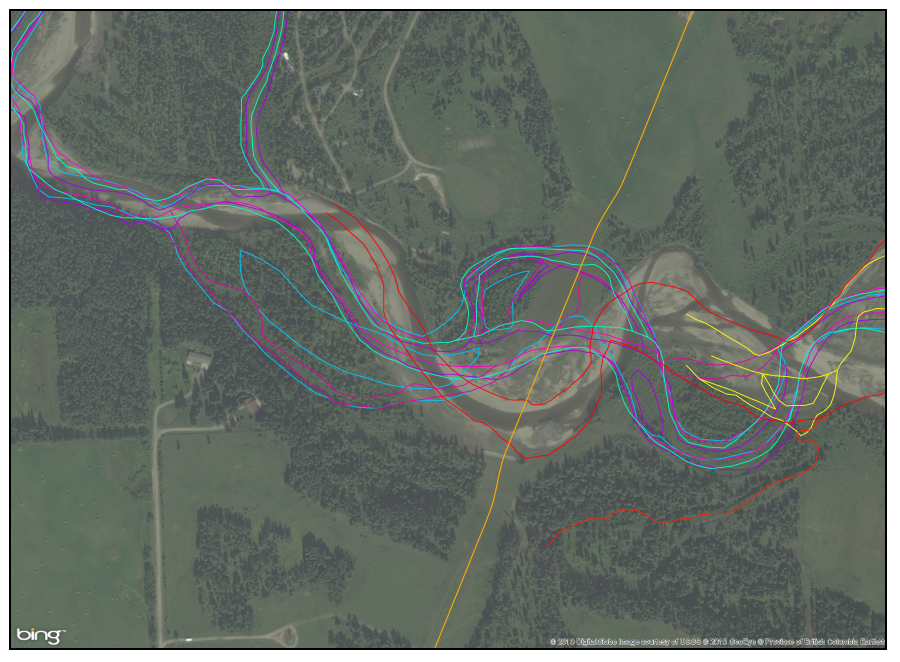

Figure 5. Imagery of the James River crossing (Bing Maps 2012) showing the pipeline (orange), and bank outlines for 1980 (blue), 1982 (pink), 1985 (purple), 1987 (turquoise), 2003 (yellow) and 2005 (red). North is up. Flow direction is to the right.

\subsection{Erosion rates}

The resistance of soil to erosion is a function of soil type, as shown by the Shield's diagram relationship between particle size and incipient motion (Briaud 2008). Briaud and co-workers have extended this relationship to include fine grained soils, as the assumption that fine grained silt or clay would erode at the same rate as fine sand was shown to be too conservative.

Following both laboratory and field scale testing, Briaud proposed several erosion categories based on measured rates of erosion, which were then correlated to soil classifications, as shown in Figure 6 (Briaud 2008). Figure 6 summaries the expected erodibility relationship between soil type and applied velocity, which can be used to establish threshold velocities below which no erosion is expected, and predictions of the rates of erosion ( $\mathrm{mm} /$ hour) for velocities which exceed the threshold.

The screening bank erosion assessment method uses classification of bank soil type to define threshold velocities. In the case of the James River (shown in Table 2), if the threshold velocity is $2 \mathrm{~m} / \mathrm{s}$, based on the soil in the banks it is apparent that no erosion is expected to occur on the left bank, and erosion is only predicted for floods above a return period of 20 years on the right bank.

The higher the velocity is above the threshold, the higher the expected peak erosion rate. Applying the conversion between the velocity and the peak erosion rate defined by Briaud et al. 2011, the flood hydrographs are replotted to show flood duration verses erosion rate. Using the flood hydrograph, the estimated amount of bank erosion is a function of the effective time to peak and the maximum erosion rate. The amount of erosion $(\mathrm{mm})$ is determined by integrating the area under the triangle. The effective time to peak accounts for the duration of the flood event above the threshold velocity.

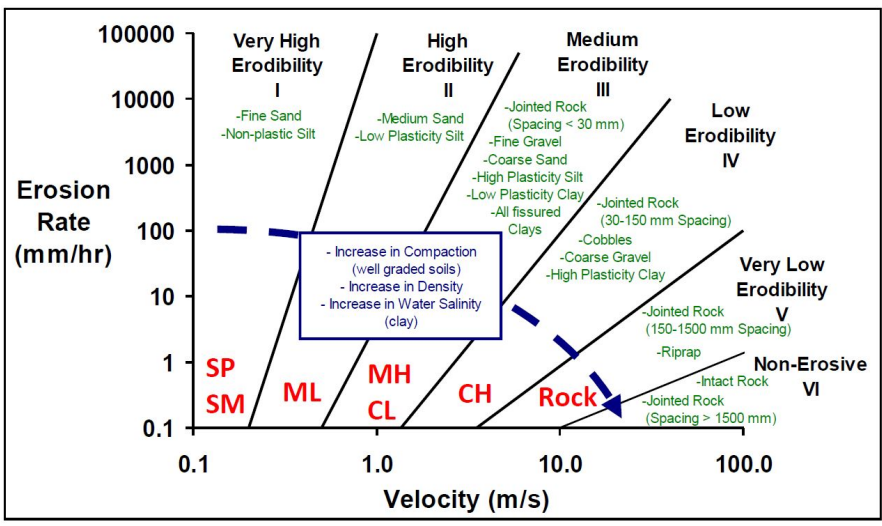

Figure 6. Velocity versus erosion rate relationship (Briaud et al. 2011).

\subsection{Probability of exposure}

The amount of erosion calculated for each bank and return period is compared to the setback distance, which is, the minimum horizontal distance that the bank can move, have the same bed elevation until the pipeline becomes exposed. The smallest flood that would erode to the pipeline is then considered the exposure flood and its return period is equal to the probability of exposure of the pipeline due to bank erosion.

Since 2013, field data have been collected that would allow the screening bank erosion assessment method to be used at approximately 5,000 pipeline watercourse crossings. Site visits are completed using standardized field forms to collect necessary information in 15 to 45 minutes depending on the size and complexity of the site (Baumgard et al. 2014). This information, combined with the estimates of the magnitude and duration of floods with different return periods, is used to calculate the return period of flood, up to a flood with a return period of 500years, which would expose the pipeline due to bank erosion.

\section{RESULTS AND DISCUSSION}

In order to validate the screening method, the results were compared to those obtained from detailed studies. A description of the detailed methodology for measuring bank erosion has recently been described (Roberge et al. 2016) and consists of: 1) identifying the study reach, 2) compiling a flood history from the relevant river gauge data, 3) obtaining historical air photographs bounding significant flood dates, 4) georeferencing or orthorectifying the air photos, 5) delineating the watercourse banks, 6) measuring the historical bank erosion based on the changes in the bank positions in the air photos, 7) combining the results to compare the measured bank position change 
that occurred between successive air photos and assign all this erosion to the largest return period flood that occurred within that period. This correlation exercise has been completed using air photographs and repeat surveys for approximately 70 separate pipeline crossings.

The results of the detailed study showed that bank erosion does not necessarily increase with larger floods (Roberge et al. 2016). The magnitude of bank erosion was better correlated to the planform river classification and bankfull width than to the flood return period. The results of the detailed study for the normalized bank erosion (bank erosion (BE) divided by bankfull width (BF)) are summarized for rivers having different classifications according to Church 2006 (Table 3).

Table 3. Typical range of normalized stream class erosion values (Roberge et al. 2016).

\begin{tabular}{lcc}
\hline $\begin{array}{l}\text { Church (2006) Classification } \\
\text { Classification }\end{array}$ & $\begin{array}{l}\text { Minimum } \\
\mathrm{BE} / \mathrm{BF}^{*}\end{array}$ & $\begin{array}{c}\text { Maximum } \\
\mathrm{BE} / \mathrm{BF}^{*}\end{array}$ \\
\hline Straight & 0.00 & 0.10 \\
Meandering - low sinuosity & 0.00 & 0.20 \\
Meandering - moderate sinuosity & 0.05 & 0.35 \\
Meandering - high sinuosity & 0.05 & 0.20 \\
Wandering & 0.10 & 0.60 \\
\hline
\end{tabular}

* Bank erosion normalized by bankfull width.

The results summarized in Table 3 are consistent with other published studies, such as those available for confined meandering rivers (Nicoll \& Hicken 2010) where the normalized migration (migration distance divided by bankfull width) varied from 0 to 0.12 with a median value of 0.02 . The values shown in Table 3 represent general trends; erosion amounts have occurred outside of these ranges, with the largest amount of bank erosion encountered having a $\mathrm{BE} / \mathrm{BF}$ ratio of 1 (Roberge et al. 2016).

Two examples where the screening level results are compared to detailed measurements are presented; one for a wide (bankfull of $460 \mathrm{~m}$ ) meandering river and one for wide (bankfull of $125 \mathrm{~m}$ ) wandering river in Canada. An example of a large meandering river crossing in the Canadian prairie province of Saskatchewan is shown in Figure 7. The position of the banks recorded from various air photographs are shown as different colour lines on the image.

A detailed study was undertaken at this crossing to measure the bank erosion that occurred between the air photographs and correlate the erosion with the largest return period flood that occurred in the intervening time period. The results of the study were compared to screening level results based on a site visit completed at the crossing in 2014. As shown in Figure 8, the screening methodology correlates quite well with measured bank erosion for the river.

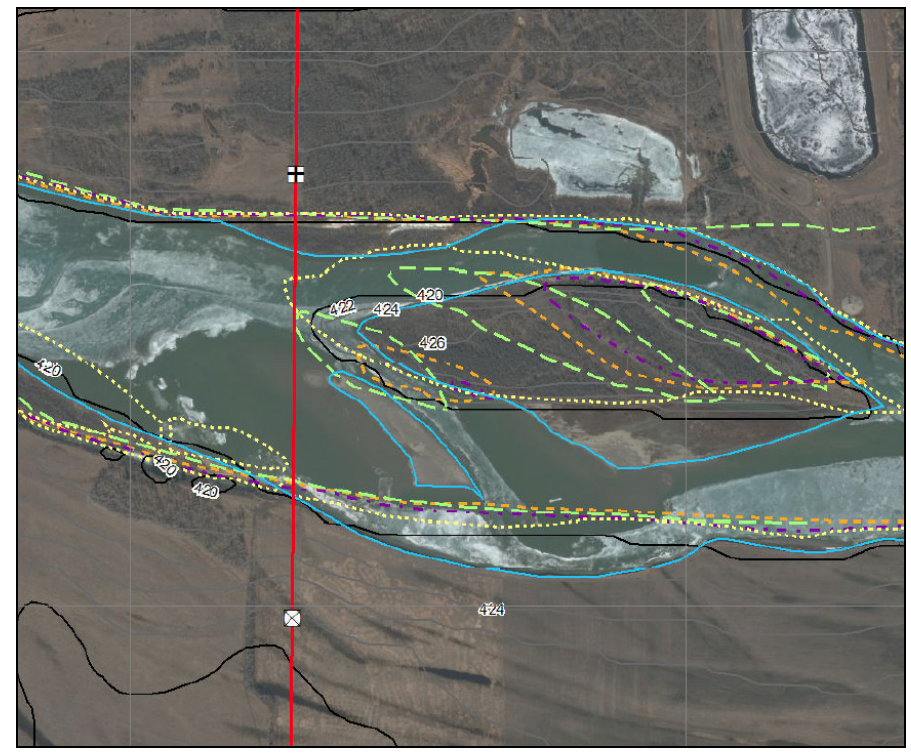

Figure 7. Imagery of the North Saskatchewan River crossing (Bing Maps 2012) showing the pipeline (red), and bank outlines for 1927 (green), 1950 (orange), 1969 (purple) and 1985 (yellow). North is up. Flow direction is to the right.

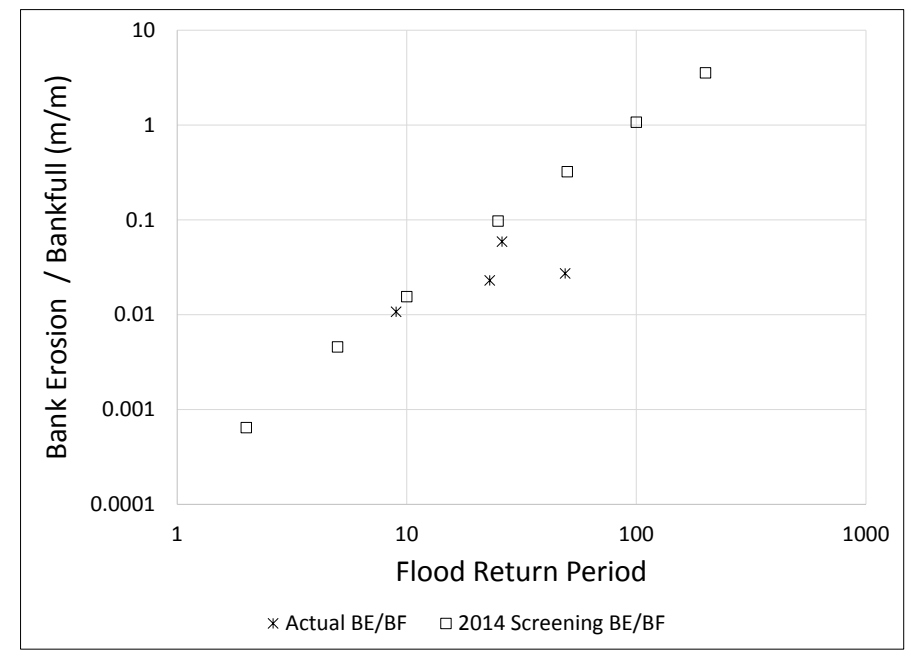

Figure 8. Measured bank erosion versus return period of flood for predicted bank erosion for the North Saskatchewan River based on the screening model 2014 and actual bank erosion for assigned to floods between 1927 until 2012.

Figure 9 shows an aerial image of the Elbow River, a wandering river in Alberta, with the position of the banks of the banks plotted at different time periods based on air photographs. As was completed at the North Saskatchewan River, the normalized bank erosion is plotted versus the maximum return period flood that occurred between air photos in Figure 10. 


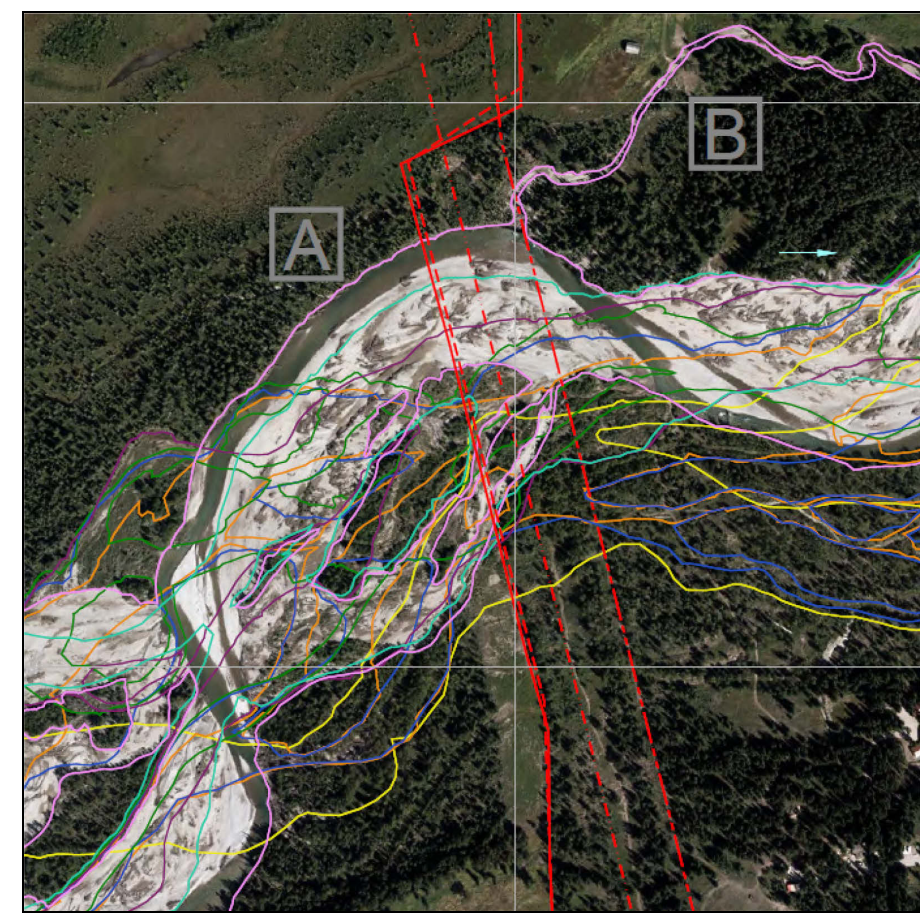

Figure 9. Imagery of Elbow River crossing (Google Earth 2014) with pipelines (red) and bank outlines for 1949 (yellow), 1966 (orange), 1970 (blue), 1983 (green), 1998 (purple), 2005 (turquoise), and 2014 (pink). North is up. The arrow shows flow direction. ' $A$ ' denotes the northern bend where bank erosion is a hazard. ' $\mathrm{B}$ ' shows a potential avulsion channel.

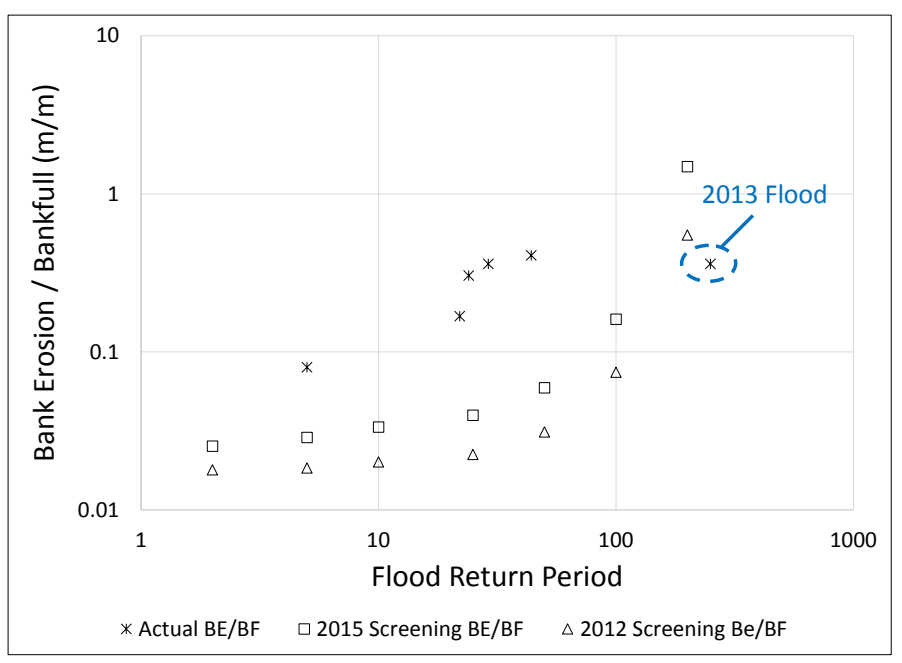

Figure 10. Measured bank erosion versus return period of flood for predicted bank erosion for the Elbow River based on the screening model from 2012 and 2015 and actual bank erosion for assigned to floods between 1949 until 2014. The circled actual BE/BF represents the 2013 flood.

Two screening level results are plotted in Figure 10 , which correspond to two site visits, one from 2012 and one from 2015. The 2012 result represents the field conditions prior to the large flood that occurred on this river in 2013, while the 2015 result provides an assessment of the current conditions. Although the measured bank erosion and the model results does not match in general, it did produce a good match between the prediction of the 200-year return flood and the 2013 flood. At this particular crossing, the pipeline was deeply buried throughout the floodplain in anticipation of this type of lateral migration, so that the bank erosion is not likely to cause a pipeline exposure.

The correlation between the predicted bank erosion from the screening model and measured erosion is rather poor in Figure 10, one of the worst encountered as part of the verification process. Explanations for this include: the 2012 or 2015 bank conditions may not be representative of earlier bank conditions; multiple floods slightly less than the maximum flood are included in the longer periods between successive air photos (over estimate of the bank erosion assigned to a single event); the effect large woody debris; and the simplification of the flood hydrograph compared to actual discharge.

\section{CONCLUSION}

A screening method to estimate the probability of pipeline exposure due to bank erosion was presented. The method uses flood hydrographs, peak discharges, times to peak and water velocities generated based on screening level FFAs created from a GIS based river network. Based on the erodibility of the bank material and the duration of the flood above the threshold velocity to initiate erosion of the material, an estimate of bank erosion is calculated. When this is compared to the available horizontal distance between the pipeline and the bank, the return period of the flood to cause exposure is estimated.

Comparison between the screening level results and the 70 sites studied as part of Roberge et al. 2016 was completed to validate the model. Results suggested acceptable correlation of the screening model to the empirical data.

The screening bank erosion method is not proposed as a replacement of detailed studies, rather it can be used to prioritize large numbers of pipeline crossings for additional investigation based on the probability of pipeline exposure.

\section{REFERENCES}

Alberta Energy Regulator, 2013, Report 2013-B: Pipeline Performance in Alberta, 1990-2012. www.aer.ca, Alberta Energy Regulator, Calgary, AB

Alberta Transportation, 2006, Development of Runoff Depth Map for Alberta. http://www.transportation.alberta.ca/Content/docType30/Pr oduction/DvRnoffDMap.pdf

Bracic, J.J., Malcovish, C. and Yaremko, E. 2014 Risk management for lateral channel movement at pipeline water crossings. 2014 International Pipeline Conference, Calgary, Alberta, IPC2014-33632, ASME

Briaud, J.-L. 2008 Case Histories in Soil and rock Erosion: Woodrow Wilson Bridge, Brazo River Meander, Normany Cliffs, and New Oreans Levees, Fourth International Conference on Scour and Erosion.

Briaud, J.-L., Chen, H.C., Chang, K.-A., Oh, S.J., Chen, S., Wang, J. Li, Y., Kwak, K., Nartjaho, P., Gudaralli, R., Wei, W., Pergu, S., Cao, Y.W. \& Ting, F. 2011 The SRICOS- 
EFA Method: A summary report, Texas A\&M internal university report.

Church, M. 2006. Bed material transport and the morphology of alluvial river channels. Annu. Rev. Earth Planet. Sci. 34, 325-354.

Cunha, S. 2012. Comparison and Analysis of Pipeline Failure Statistics. Proceedings of IPC 2012, Calgary.

Dooley, C., Prestie, Z., Ferris, G., Fitch, M. and Zhang, H. 2014. Approaches for Evaluating the Vulnerability of Pipelines at Water Crossings. 2014 International Pipeline Conference, Calgary, Alberta, Canada, IPC2014-32240, ASME

Eaton, B.C. \& Millar, R.G. 2004. Optimal alluvial channel width under a bank stability constraint. Geomorphology; vol. 62, issue 1-2, pg. 35-45

Ferris, G., Newton, S., Ho, M., Eichhorn, G. and Bear, D. 2015 Flood Monitoring for Buried Pipeline Watercourse Crossings. Rio Pipeline Conference and Exposition 2015, IPB1091_15

Jeglic, F. $20 \overline{0} 4$. Analysis of ruptures and trends on major Canadian pipeline systems. Proceedings of IPC 2004, Calgary, IPC04-0474

Leopold, L.B. 1994. A View of the River. Harvard University Press, Cambridge, USA

Porter, M., Leir, M., Baumgard, A., and Ferris, G. 2014. Integrating terrain and geohazard knowledge into the pipeline lifecycle. Proceedings of the 6th Canadian GeoHazards Conference - GeoHazards 6, Kingston, Canada. June 15$18,2014$.

Roberge, L., Ferris, G. and Weatherly, H. 2016. Past Bank Erosion as a guide for Bank Erosion Prediction at Pipeline Crossings. 2016 International Pipeline Conference, Calgary, ASME, in press

NTSB 1996 Evaluation of pipeline failures during flooding and of spill response actions, San Jacinto River near Houston, Texas, October 1994, NTSB/SIR-96/04

Nicoll, T.J. \& Hicken, E.J. 2010 Planform geometry and channel migration of confined meandering rivers on the Canadian Prairies. Geomorphology 116 (37-47).

Thorne, C.L. \& Abt, S.R. 1993. Velocity and scour predictions in river bands. USACE contract report HL-93-1, USACE

Watt, W. E. (editor) 1989 Hydrology of Floods in Canada: A guide to planning and design. National research council of Canada, Ottawa 